\title{
Retrograde Lymph Flow Leads to Chylothorax in Transgenic Mice with Lymphatic Malformations
}

\author{
Maximilian Nitschké, ${ }^{*}$ Alexander Bell, ${ }^{*}$ Sinem Karaman, ${ }^{\dagger}$ Meelad Amouzgar, ${ }^{*}$ Joseph M. Rutkowski,,${ }^{\ddagger}$ Philipp E. Scherer, \\ Kari Alitalo, ${ }^{\dagger}$ and Donald M. McDonald ${ }^{*}$
}

\begin{abstract}
From the Department of Anatomy, * Cardiovascular Research Institute, and UCSF Helen Diller Family Comprehensive Cancer Center, University of California San Francisco, San Francisco, California; the Wihuri Research Institute and Translational Cancer Biology Research Program, ${ }^{\dagger}$ University of Helsinki, Helsinki, Finland; the Division of Lymphatic Biology, ${ }^{\ddagger}$ Department of Medical Physiology, Texas A\&M College of Medicine, College Station, Texas; and the Touchstone Diabetes Center, ${ }^{\S}$ Department of Internal Medicine, University of Texas Southwestern Medical Center, Dallas, Texas
\end{abstract}

Accepted for publication

May 22, 2017.

Address correspondence to Donald M. McDonald, M.D., Ph.D., University of California, San Francisco, 513 Parnassus Ave, Room S1349, San Francisco, CA 94143-0452. E-mail: donald.mcdonald@ucsf.edu.
Chylous pleural effusion (chylothorax) frequently accompanies lymphatic vessel malformations and other conditions with lymphatic defects. Although retrograde flow of chyle from the thoracic duct is considered a potential mechanism underlying chylothorax in patients and mouse models, the path chyle takes to reach the thoracic cavity is unclear. Herein, we use a novel transgenic mouse model, where doxycycline-induced overexpression of vascular endothelial growth factor (VEGF)-C was driven by the adipocyte-specific promoter adiponectin (ADN), to determine how chylothorax forms. Surprisingly, $100 \%$ of adult ADN-VEGF-C mice developed chylothorax within 7 days. Rapid, consistent appearance of chylothorax enabled us to examine the step-by-step development in otherwise normal adult mice. Dynamic imaging with a fluorescent tracer revealed that lymph in the thoracic duct of these mice could enter the thoracic cavity by retrograde flow into enlarged paravertebral lymphatics and subpleural lymphatic plexuses that had incompetent lymphatic valves. Pleural mesothelium overlying the lymphatic plexuses underwent exfoliation that increased during doxycycline exposure. Together, the findings indicate that chylothorax in ADN-VEGF-C mice results from retrograde flow of chyle from the thoracic duct into lymphatic tributaries with defective valves. Chyle extravasates from these plexuses and enters the thoracic cavity through exfoliated regions of the pleural mesothelium. (Am J Pathol 2017, 187: 1984-1997; http://dx.doi.org/10.1016/j.ajpath.2017.05.009)
Chylothorax is a pleural effusion in which chyle accumulates in the thoracic cavity. Chyle is the milky fluid rich in triglycerides, proteins, and lymphocytes that originates from lacteals in the small intestine. ${ }^{1,2}$ Long-chain triglycerides packed into chylomicrons are taken up by lacteals in villi of the small intestine and transported as chyle through mesenteric lymphatic vessels into the thoracic duct. In healthy adults, chyle from the small intestine and lymph from other parts of the body are transported at rates of up to $4 \mathrm{~L}$ a day through the thoracic duct into venous blood at the lymphovenous junction near the left subclavian vein. ${ }^{3}$

Chylothorax can result from leakage from the thoracic duct after surgery, trauma, or obstruction by tumors. ${ }^{4}$ Chylothorax can also occur spontaneously in newborns, where it is the most common form of pleural effusion, ${ }^{5}$ occurring in $1: 10,000$ to $1: 15,000$ pregnancies. ${ }^{6}$
Congenital chylothorax is found in some children with Noonan, Turner, or Hennekam syndromes, or other malformations involving the lymphatic system..$^{7-11}$ Congenital chylothorax has been linked to point mutations of SOX18, $C C B E 1$, ephrin type-B receptor 4 , and integrin- $\alpha 9 .{ }^{12-15}$ All of these genes play roles in lymphatic valve formation or lymphangiogenesis in mice. ${ }^{16-19}$

Mutant mouse models have proved to be valuable tools for elucidating links between the genetic and

Supported in part by National Heart, Lung, and Blood Institute, NIH, grants P01 HL024136, R01 HL059157, and R01 HL127402 (D.M.M.), the Leducq Foundation Transatlantic Network of Excellence grant 11CVD03, Lymph Vessels in Obesity and Cardiovascular Disease grant 11CVD03 (K.A. and D.M.M.), the Angel-Works Foundation (D.M.M.), and the Swiss National Science Foundation grants PBEZP3_145983 (M.N.) and P300PB_164732 (S.K.).

Disclosures: None declared. 
pathophysiological basis of lymphatic abnormalities. Such studies have revealed that chylothorax frequently accompanies lymphatic valve defects ${ }^{18,20-22}$ and widespread lymphatic malformations in mice. ${ }^{23-28}$

Not much is known of how lymphatic malformations and lymphatic valve defects result in chylothorax in patients, but retrograde flow of chyle from the thoracic duct into the chest has been suggested. ${ }^{29,30}$ Consistent with this process, lymphatic valve defects have been reported in conditions where chyle is found in patient sputum. ${ }^{31}$ Retrograde flow of chyle from the thoracic duct toward peribronchial lymphatics has also been shown by lymphangiography in patients with plastic bronchitis, where lymph accumulates and forms solid casts in airways. ${ }^{32}$ Most of these patients have chylothorax.

Retrograde flow of chyle from the thoracic duct has been proposed in mice with chylothorax. ${ }^{21,24,25}$ However, the underlying mechanism and route of lymph flow into the thoracic cavity has not been determined. Also unknown is how chyle leaves the thoracic duct and enters the thoracic cavity. Most mouse models are limited by the development of chylothorax soon after birth, followed by death soon thereafter. ${ }^{20,23,25,28}$ In other models, chylothorax develops later in life but has an unpredictable incidence. ${ }^{21,22,27}$

We generated mice where vascular endothelial growth factor (VEGF)-C is conditionally overexpressed in adipocytes with the initial intent of determining whether expansion of the lymphatic network in adipose tissue would reduce inflammation and the incidence of metabolic syndrome on a high-fat diet. Unexpectedly, these mice uniformly developed chylothorax, which could be lethal within a week of activation of VEGF-C expression. This model provided the opportunity to learn, step by step, about the pathophysiology of chylothorax associated with lymphatic malformations. We, therefore, sought to determine the time course, route of chyle flow, and abnormalities in the lymphatic vasculature that led to chylothorax. We also sought to learn where chyle leaves lymphatics, crosses the pleural mesothelium, and enters the thorax.

The studies revealed that VEGF-C overexpression in adipocytes led to lymphatic vessel enlargement and loss of competent valves, which enabled retrograde flow of chyle from the thoracic duct into paravertebral lymphatics and adjacent lymphatic plexuses. Chyle extravasated from the plexuses and entered the thoracic cavity, where it resulted in exfoliation of the pleural mesothelium.

\section{Materials and Methods}

\section{Generation of Double- and Triple-Transgenic Mice}

Adiponectin-rtTA tetO-VEGF-C double-transgenic mice [designated adiponectin (ADN)-VEGF-C mice] were generated by breeding mice of the adiponectin-rtTA driver strain $\left(\mathrm{C} 57 \mathrm{BL} / 6\right.$ background) ${ }^{33}$ with mice of the tetO-mVEGF-C responder strain (FVB background). ${ }^{34}$ Experiments were performed on mice of $\mathrm{F}_{1}(\mathrm{BL} / 6 \times \mathrm{FVB})$ or $\mathrm{F}_{2}(\mathrm{~F} 1 \times$ FVB) background at 8 to 12 weeks of age. Single transgenic littermates were used as controls. Some transgenic mice were crossed with Prox 1-green fluorescent protein (GFP) mice (FVB background) ${ }^{35}$ to make ADN-VEGF-C/Prox1-GFP triple-transgenic mice with green fluorescent lymphatics $\left(\mathrm{F}_{1}, \mathrm{FVB}\right.$ background). Prox 1-GFP ${ }^{+}$littermates were used as controls in these experiments. VEGF-C overexpression was induced in transgenic mice by administration of doxycycline (Sigma-Aldrich, St. Louis, MO; $0.075 \mathrm{mg} / \mathrm{mL}$ in $5 \%$ sucrose) in the drinking water for 7 days, unless otherwise indicated. This protocol was based on initial studies of mice that received doxycycline in concentrations ranging from 0.025 to $0.1 \mathrm{mg} / \mathrm{mL}$ in $5 \%$ sucrose for 7 days or doxycycline at 0.075 $\mathrm{mg} / \mathrm{mL}$ for 1 to 7 days. Mice were housed under barrier conditions and were anesthetized by i.m. injection of $87 \mathrm{mg} /$ $\mathrm{kg}$ ketamine and $13 \mathrm{mg} / \mathrm{kg}$ xylazine before experimental procedures. All experiments were approved by the Institutional Animal Care and Use Committee of the University of California-San Francisco.

\section{Tissue Preparation and Whole Mount Staining}

Tissues were fixed by vascular perfusion of fixative $[1 \%$ paraformaldehyde in phosphate-buffered saline (PBS); $\mathrm{pH}$ 7.4] through the left ventricle for 2 minutes at 120 to $140 \mathrm{~mm}$ $\mathrm{Hg}$. Trachea, intestinal mesenteric fat, gonadal fat adjacent to epididymis or uterus, subcutaneous fat near the inguinal lymph node, and dorsal ear skin were prepared as whole mounts for immunofluorescence staining. Primary antibodies, either individually or mixtures of two, were diluted in PBS containing $0.3 \%$ Triton $\mathrm{X}-100,10 \%$ normal serum, and $0.1 \%$ sodium azide. Lymphatics were stained for lymphatic vessel endothelial hyaluronan receptor 1 (LYVE-1; AngioBio, San Diego, CA; 1:500, rabbit polyclonal 11-034). Adipocytes were stained for perilipin (Abcam, Cambridge, UK; 1:1000, goat polyclonal AB61682; or Fitzgerald, North Acton, MA; 1:500, guinea pig polyclonal 20R-PP004). Lymphatics in Prox1-GFP mice were stained for GFP (Aves Labs, Inc., Tigard, OR; 1:1000, chicken polyclonal GFP-1020). Primary antibodies were detected with species-specific secondary antibodies labeled with Cy3, Alexa Fluor 488, or Cy5 (Jackson ImmunoResearch Laboratories Inc., Westgrove, PA; 1:500). Specimens were examined with a Zeiss Axiophot fluorescence microscope (Zeiss USA, Thornwood, NY) and imaged with an Olympus DP73 video camera (Olympus USA, Center Valley, PA) with CellSens Dimensions version 1.13 (Olympus USA) or Zeiss LSM-510 confocal microscope (Zeiss USA) with AIM 4.0 confocal software (Zeiss USA).

Lymphatics in whole mounts of the chest wall were examined after staining for LYVE-1 or GFP. Primary antibodies were detected by biotinylated species-specific secondary antibodies and streptavidin conjugated to horseradish peroxidase (Jackson ImmunoResearch Laboratories Inc.; 1:500) and developed using ImmPACT diaminobenzidine substrate and peroxide (Vector, Burlingame, CA; SK-4103). Specimens were examined with a Zeiss Lumar V12 fluorescence stereomicroscope with illumination by model HXP 
A

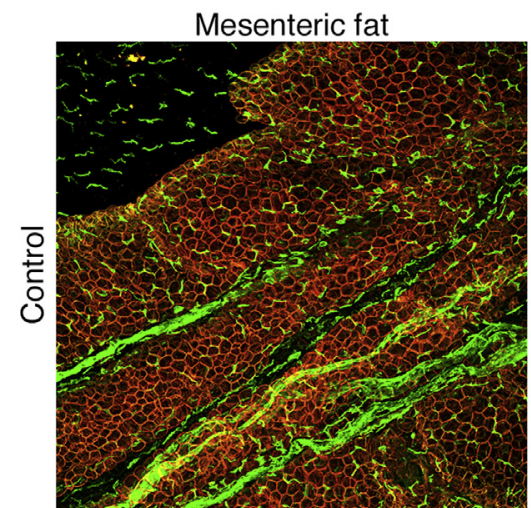

Trachea
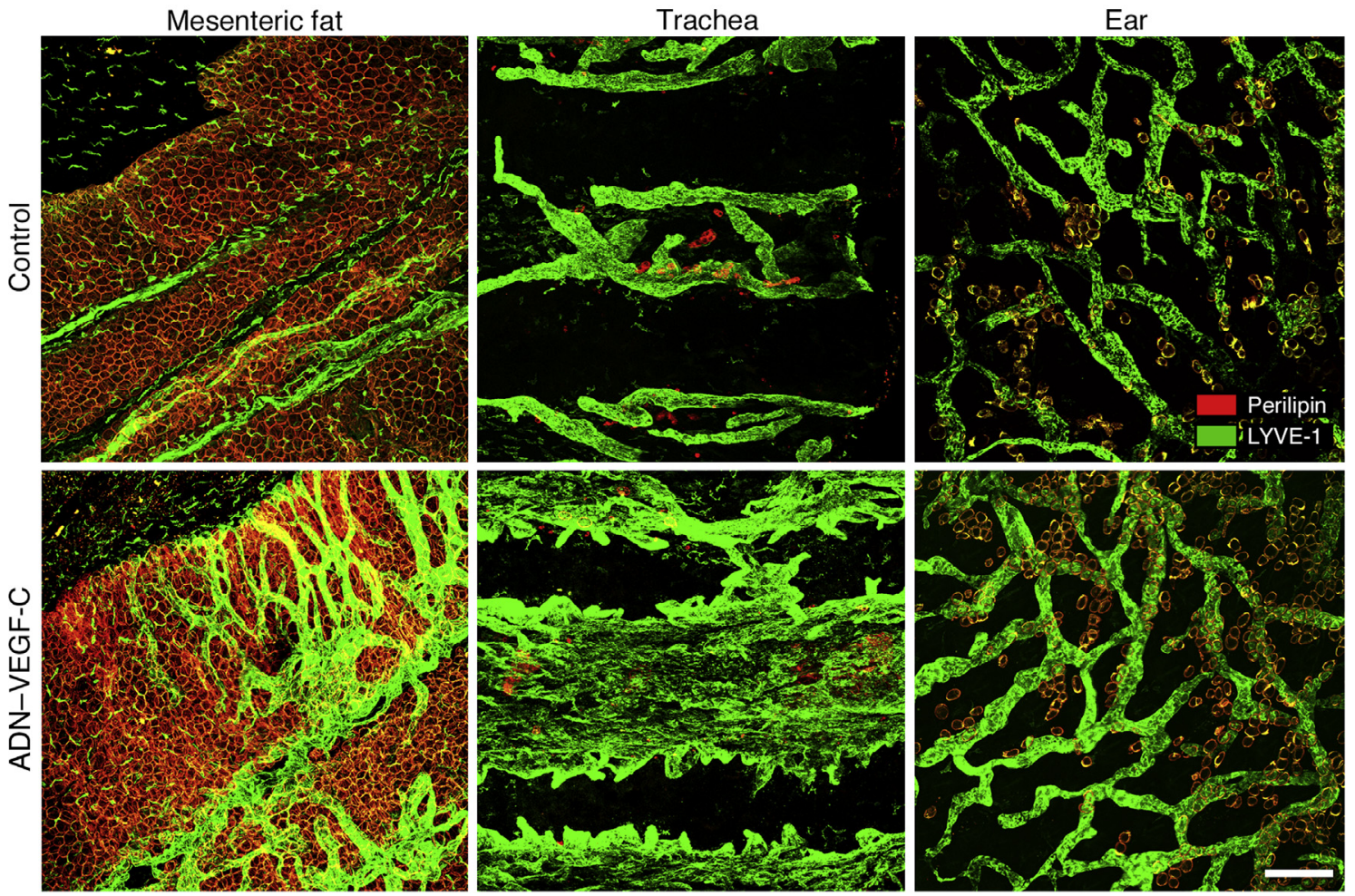

B

C

D

mRNA expression (compared to ear) Adiponectin

Vegfc

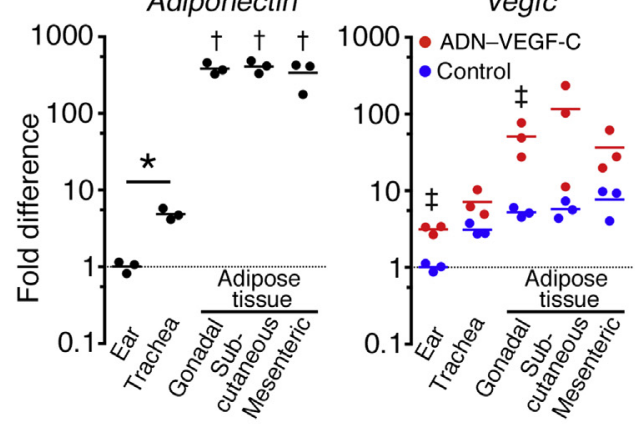

Chyle in thorax

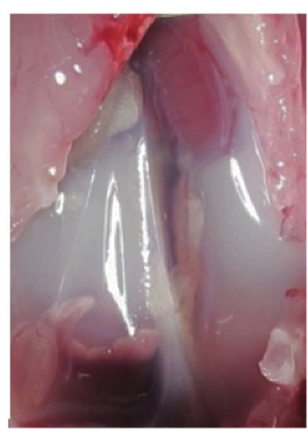

Chyle accumulation over time

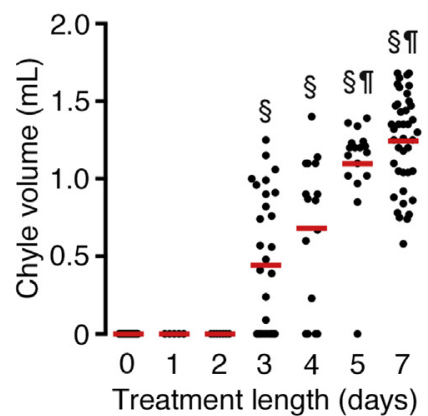

$\mathbf{E}$

Incidence of chylothorax and chylous ascites

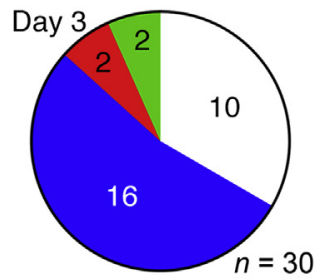

$\square$ Chylothorax only

$\square$ Chylous ascites only

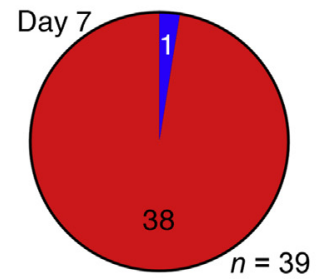

Neither

Both
Correlation of lymphangiogenesis and chyle volume

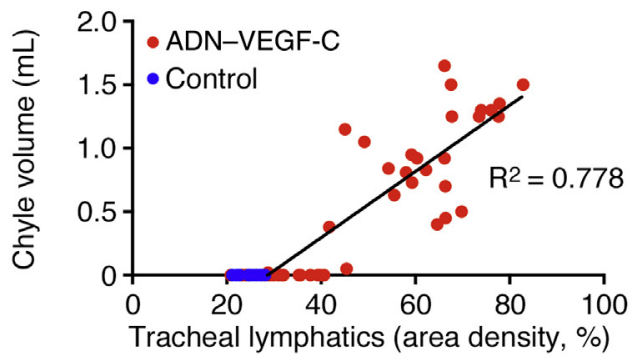


$120 \mathrm{C}$ light source. Images were acquired with a Zeiss AxioCam MRc color camera or MRm high sensitivity monochrome camera for time-lapse video recording.

\section{Quantitative Real-Time PCR}

Expression of adiponectin and Vegfc in organs of control mice and ADN-VEGF-C mice after $0.075 \mathrm{mg} / \mathrm{mL}$ doxycycline for 7 days was measured by quantitative real-time PCR. Total RNA from ear and trachea was extracted using TRIsure (Bioline, London, UK) with phenol-chloroform, followed by column isolation using a Nucleospin RNA kit (Macherey Nagel, Düren, Germany). Total RNA from adipose tissue was isolated using an RNeasy Lipid Tissue Mini kit (Qiagen, Hilden, Germany), following manufacturer's instructions. cDNA was synthesized from $800 \mathrm{ng}$ total RNA using the High Capacity Reverse Transcription kit (Applied Biosystems, Foster City, CA). Quantitative real-time PCR was performed using the following primer pairs: Vegfc, 5'-GAGGTCAAGGCTTTTGAAGGC-3' (forward) and 5'-CTGTCCTGGTATTGAGGGTGG-3' (reverse); adiponectin, 5'-GGAGATGCAGGTCTTCTT-3' (forward) and 5'-CGAATGGGTACATTGGGAAC- $3^{\prime}$ (reverse); and 36b4, $5^{\prime}$-GGACCCGAGAAGACCTCCTT-3' (forward) and 5'-GCACATCACTCAGAATTTC-3' (reverse). The PCRs were set by using $20 \mathrm{ng}$ of template cDNA per reaction and FastStart SYBR Green master mix (Roche, Basel, Switzerland), according to the manufacturer's instructions, and each reaction was run in duplicate in a BIO-RAD C1000 Thermal cycler (Bio-Rad, Hercules, CA), according to standardized protocols.

Gene expression fold changes were calculated using $2^{-\Delta \Delta \mathrm{CT}}$ method, as described, ${ }^{36}$ by first calculating the $\Delta \mathrm{Ct}$ values by subtracting the $\mathrm{Ct}$ values of $36 \mathrm{~b} 4$ (acidic ribosomal phosphoprotein $\mathrm{P} 0$, the internal control) from the $\mathrm{Ct}$ values of the target genes (Vegfc or adiponectin), which results in the normalization of target gene values to the internal control for each sample. This was followed by obtaining $\Delta \Delta \mathrm{Ct}$ values by calculating an average of $\Delta \mathrm{Ct}$ values from the ear samples of control mice (as this had the lowest levels of Vegfc expression) and then subtracting this value from the individual $\Delta \mathrm{Ct}$ values, which normalized the $\Delta \mathrm{Ct}$ values to the average value for normal ear skin. Gene expression fold changes were then determined by calculating $2^{-\Delta \Delta C T}$. This calculation set the control ear levels to 1 ; gene expression fold changes of other tissues were expressed relative to the control ear values.

\section{Scanning Electron Microscopy}

Tissues were fixed by vascular perfusion of fixative (2\% glutaraldehyde in $0.1 \mathrm{~mol} / \mathrm{L}$ phosphate buffer; $\mathrm{pH} 7.4$ ) through the left ventricle for 2 minutes at 120 to $140 \mathrm{~mm} \mathrm{Hg}$. The dorsal half of the chest wall was divided in the midline and prepared as whole mounts. Specimens were removed, fixed for an additional hour ( $2 \%$ glutaraldehyde in $0.1 \mathrm{~mol} / \mathrm{L}$ phosphate buffer; $\mathrm{pH} 7.4$ ), immersed in $1 \% \mathrm{OsO}_{4}$ in water for 1 hour, dehydrated in ethanol, critical point dried in liquid carbon dioxide, sputter coated with gold/palladium alloy, and examined with a JEOL NeoScope JCM-5000 scanning electron microscope (SEM; JEOL, Tokyo, Japan).

\section{Measurements}

\section{Lymphatic Vessel Area Density}

The fractional area of lymphatic vessels stained for LYVE-1 immunoreactivity was measured on maximum intensity projections of confocal microscopic image stacks of individual intercartilage rings (tracheal whole mounts) or total adipocyte area (mesenteric fat whole mounts) using ImageJ software version 1.48k (NIH, Bethesda, MD; http://imagej.nih.gov/ij). The area density of lymphatics was calculated as the percentage of total pixels with fluorescence intensity equal to or greater than the threshold value (set at 70 to 100 for different fluorophores, within the fluorescence intensity range of 0 to 255).

\section{Lymphatic Plexus Size}

The size of lymphatic plexuses was measured in LYVE1-horseradish peroxidase-stained whole mounts of the chest wall of control and ADN-VEGF-C mice. Regions of lymphatic plexuses imaged with the fluorescence stereomicroscope were outlined using the ImageJ polygon tool, and the areas were measured.

\section{Mesothelial Exfoliation}

Montages were generated from SEM images obtained of the entire pleural surface of the dorsal chest wall of three

Figure 1 Lymphangiogenesis and chylothorax in ADN-VEGF-C mice. A: Projections of confocal microscopic image stacks of whole mounts of mesenteric fat, trachea, and ear skin after $0.075 \mathrm{mg} / \mathrm{mL}$ doxycycline for 7 days. Lymphatic vessels (LYVE-1; green). Adipocytes (perilipin; red). B: Quantitative real-time $\mathrm{PCR}$ of adiponectin expression in organs of control mice and Vegfc in control mice and ADN-VEGF-C mice after $0.075 \mathrm{mg} / \mathrm{mL}$ doxycycline for 7 days. $\Delta C \mathrm{Ct}$ values for expression of adiponectin and Vegfc were normalized to values for housekeeping gene $36 b 4$ and then to values for ears of control mice. Black lines, adiponectin means. Red lines, ADN-VEGF-C group means; blue lines, control group means. C: Chyle in thoracic cavity of ADN-VEGF-C mouse on doxycycline for 7 days. D: Chyle volume at days $0,1,2,3,4,5$, and 7 after start of $0.075 \mathrm{mg} / \mathrm{mL}$ doxycycline in drinking water. Red lines indicate chyle volume means. E: Chylothorax was found in $18(60 \%)$ of 30 ADN-VEGF-C mice on doxycycline for 3 days, 16 of which also had chylous ascites, and was found in all 39 ADN-VEGF-C mice on doxycycline for 7 days. Chylous ascites was found in $18(60 \%)$ of 30 mice on doxycycline for 3 days, but in only 1 ( $<3 \%$ ) of 39 mice on doxycycline for 7 days. F: Linear regression of lymphatic vessel abundance in trachea and volume of chyle in the thoracic cavity of ADN-VEGF-C mice $(n=49$, $\left.R^{2}=0.778, P=0.0001\right)$. Mice received 0.025 to $0.1 \mathrm{mg} / \mathrm{mL}$ doxycycline for 1 to 7 days. Blue dots are onset controls that received no doxycycline. $n=45$ (D, day 0$) ; n=5$ (D, day 1); $n=7$ (D, day 2); $n=30$ (D, day 3$) ; n=16$ (D, day 4); $n=17$ (D, day 5); $n=41$ (D, day 7$) ; n=49$ ADN-VEGF-C mice (F); $\mathrm{n}=10$ control mice $(\mathbf{F}) * P<0.05$ (adiponectin graph; $t$-test) ${ }^{\dagger} P<0.05$ versus ear and trachea (adiponectin graph; one-way analysis of variance); ${ }^{\ddagger} P<0.05$ ADN-VEGF-C mice versus controls (Vegfc graph; one-way analysis of variance); ${ }^{\S} P<0.05$ versus days 0,1 , and 2 ; ${ }^{\natural} P<0.05$ versus to day 3 (one-way analysis of variance). Scale bar $=200 \mu \mathrm{m}(\mathbf{A})$. 
ADN-VEGF-C mice. Regions lacking mesothelial cells (sites of mesothelial exfoliation) were colored in green (Photoshop, CS6; Adobe, San Jose, CA), measured, and expressed as percentage of total mesothelial surface area. To determine the distribution and amount of mouse-to-mouse colocalization, exfoliated regions in the three mice were aligned using vertebrae and ribs as fiduciary landmarks. Highlighted regions that colocalized in two mice were marked yellow, and regions that colocalized in all three mice were marked red. The same approach was used to determine the location of lymphatic plexuses in three Prox1-GFP control mice.

\section{Analysis of Fluorescent Tracer Leakage from Lymphatics}

After anesthesia and vascular perfusion of PBS through the left ventricle for 2 minutes at 120 to $140 \mathrm{~mm} \mathrm{Hg}$, organs in the thoracic cavity were removed to expose the thoracic duct, and the abdominal cavity was opened to expose the rostral-most mesenteric lymph node. Two minutes later, 40 $\mu \mathrm{L}$ of a solution containing $1.25 \mathrm{mg} / \mathrm{mL}$ rhodamine-labeled Ricinus communis agglutinin I (Vector; RL-1082) and 0.9\% sodium chloride was injected into a mesenteric lymph node through a 27-gauge butterfly needle with 8-inch tubing (Abbott Laboratories, Lake Bluff, IL) at 40 to $50 \mathrm{~mm} \mathrm{Hg}$. Pressure was controlled using a sphygmomanometer attached to the tubing via a water-filled 1-L aspirator bottle. Time-lapse video images of fluorescent tracer flow through the thoracic duct and adjacent lymphatics and sites of extravasation were recorded with the AxioCam MRm monochrome camera on the fluorescence stereomicroscope. To determine the amount of colocalization of the tracer with lymphatics, the chest wall was subsequently removed, fixed for 1 hour (1\% paraformaldehyde in PBS; $\mathrm{pH} 7.4$ ), and stained for LYVE-1 or GFP. Images of the fluorescent tracer and LYVE-1 or GFP immunoreactive lymphatics were superimposed and regions of colocalization identified.

\section{Intrathoracic Injection of Chyle}

Wild-type littermates were shaved over the chest and anesthetized using isoflurane. A 27-gauge 3/8-inch butterfly needle bent at a 90-degree angle was inserted into the thoracic cavity adjacent to the right side of the sternum at the level of the fourth rib, and $500 \mu \mathrm{L}$ of chyle or PBS was injected. Chyle was obtained by thoracentesis from ADN-VEGF-C mice 5 days after the onset of doxycycline $(0.075 \mathrm{mg} / \mathrm{mL})$. Twentyfour hours later, mice were euthanized, pleural fluid, if present, was withdrawn and measured, tissues were fixed by vascular perfusion, and the chest wall was prepared for SEM.

\section{Statistical Analysis}

Data are presented as dot plots with means or as bar graphs showing means \pm SEM. Differences were assessed by twotailed $t$-test or one-way analysis of variance, followed by the
Bonferroni test for multiple comparisons. The correlation between lymphatic vessel area density and volume of chyle in the thoracic cavity was assessed by linear regression. $P<0.05$ was considered statistically significant. All statistical tests were performed with Prism 6 (GraphPad, La Jolla, CA).

\section{Results}

Lymphangiogenesis and Chylothorax in ADN-VEGF-C Mice

TetO-VEGF-C responder mice were bred with mice expressing the rtTA-transgene under the adipocyte-specific ADN promoter with the intent of promoting lymphatic vessel growth in adipose tissue, which usually has few lymphatics. ${ }^{37}$ Exposure of adiponectin-rtTA tetO-VEGF-C double-transgenic mice (ADN-VEGF-C mice) to doxycycline was followed by overexpression of VEGF-C in adipocytes and extensive lymphangiogenesis in mesenteric fat (Figure 1A). Lymphatic growth was more modest in gonadal and subcutaneous fat (data not shown). Robust lymphangiogenesis was also found in the trachea, where adipocytes were scattered in intercartilage regions, but not in ear skin, despite the presence of adipocytes (Figure 1A).

Assessment of adiponectin mRNA in organs of wild-type mice revealed that adiponectin expression in tracheas was 4.8 times the value in ears. Adiponectin mRNA levels in gonadal, subcutaneous, and mesenteric adipose tissues were 340 to 400 times the values in the ear (Figure 1B). Consistent with these differences, Vegfc mRNA levels in ADN-VEGF-C mice were slightly higher in the trachea than in the ear and were highest in adipose tissue (Figure 1B). Vegfc expression in all organs of ADN-VEGF-C mice was higher than in corresponding organs of control littermates, but considerable variability was found among mice (Figure 1B).

Adult ADN-VEGF-C mice rapidly developed chylothorax while receiving doxycycline for 3 days or more (Figure 1C). To characterize the chylothorax in ADN-VEGF-C mice, doxycycline treatment regimens were compared to determine a dose and duration that consistently resulted in chylothorax and was compatible with survival. It was found that 8- to 12 -week-old mice given $0.075 \mathrm{mg} / \mathrm{mL}$ doxycycline in the drinking water for 7 days uniformly developed chylothorax (Figure 1D). Chyle was first detected in the thoracic cavity on day 3 , when it was found in $60 \%$ of mice. By day 7, all mice had chylothorax (mean chyle volume, $1243 \pm 304 \mu \mathrm{L}$ ) (Figure 1D). The overall mortality of ADN-VEGF-C mice on doxycycline was $23 \%$ by day 7 ( $n=75$ mice).

Chylous ascites was found in $60 \%$ of ADN-VEGF-C mice on day 3; 16 of 18 mice with chylous ascites also had chylothorax at 3 days. After doxycycline for 7 days, all mice had chylothorax, but only $1(<3 \%)$ of 39 mice had chylous ascites (Figure 1E). 

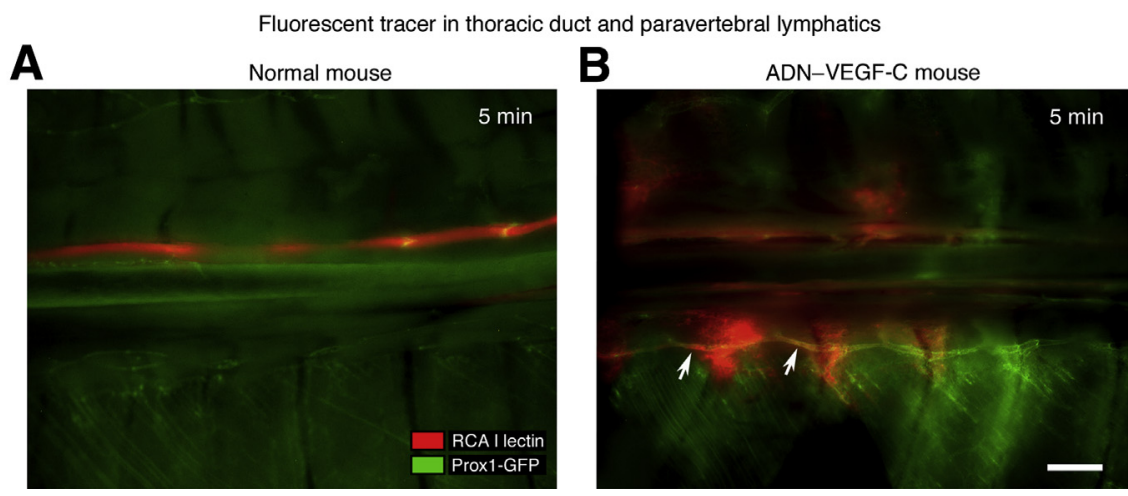

Figure 2 Abnormal flow pattern of fluorescent tracer in ADN-VEGF-C mice. Fluorescence stereomicroscopic images of Prox1-GFP control mouse (A) and ADN-VEGF-C/Prox1-GFP mouse on doxycycline for 7 days (B) showing lymphatic vessels (green) 5 minutes after injection of rhodamine-labeled Ricinus communis agglutinin I (RCA I) lectin tracer (red) into a mesenteric lymph node. Image orientation: caudal (left), rostral (right). Arrows mark tracer in paravertebral lymphatic vessel. $n=5$ mice (A and $\mathbf{B})$. Scale bar $=1 \mathrm{~mm}(\mathbf{A}$ and $\mathbf{B})$.

To determine whether the amount of chylothorax corresponded with the extent of lymphatic vessel growth, we compared the volume of chyle with the abundance of lymphatic vessels in the trachea, which served as an easily quantifiable surrogate for regions containing adipose tissue. This comparison revealed a strongly positive correlation between the volume of chyle in the thoracic cavity and the density of tracheal lymphatics in mice given doxycycline in concentrations ranging from 0.025 to $0.1 \mathrm{mg} / \mathrm{mL}$ for 7 days (Figure $1 \mathrm{~F}$ ).

\section{Leakage of Chyle from Tributaries of the Thoracic Duct}

To identify the route of chyle flow into the thoracic cavity, rhodamine-labeled Ricinus communis agglutinin I lectin was injected into a mesenteric lymph node as a tracer immediately after euthanasia of ADN-VEGF-C/Prox1-GFP tripletransgenic mice and Prox1-GFP control mice on day 7 after the onset of doxycycline and imaged the thoracic cavity 5 minutes later. In Prox 1-GFP control mice, the fluorescent tracer was confined to the thoracic duct (Figure 2A). By comparison, in ADN-VEGF-C/Prox1-GFP mice, the tracer was found in the thoracic duct, paravertebral lymphatic vessels parallel to the thoracic duct (Figure 2B), and the thoracic cavity.

To learn more about the path and dynamics of the tracer entry into the thoracic cavity, time-lapse video images of the thorax during and after the injection were acquired. Unlike the tracer in control mice, which stayed within the thoracic duct (Figure 3, A and B, and Supplemental Video S1), the tracer was found in paravertebral lymphatics a few seconds after appearance in the thoracic duct in 26 (90\%) of 29 ADN-VEGF-C mice (Figure 3, C and D, and Supplemental Video S2). No tracer was found in paravertebral lymphatics of $3(10 \%)$ of 29 ADN-VEGF-C mice. Tracer flow out of the thoracic duct into paravertebral lymphatics was opposite (retrograde) to the normal direction of lymph flow. Tracer beyond the paravertebral lymphatics had a diffuse appearance, consistent with extravasation into the thoracic cavity (Figure 3C). These sites were distributed segmentally along the length of the paravertebral lymphatics. To test whether the diffuse tracer was free in the thoracic cavity, images were compared before and after flushing the pleural surface with PBS. Much of the diffuse tracer was washed away, as expected for tracer free in the thoracic cavity (Figure 3E), but tracer within lymphatics and interstitium remained (Figure 3E).

\section{Coincidence of Leakage and Lymphatic Plexuses}

To learn more about the architecture of lymphatics in regions of leakage, whole mounts of the thorax of Prox1GFP mice stained for GFP by immunohistochemistry were examined. In these mice, lymphatics and lymphatic valves were clearly marked by GFP. Segmental lymphatic plexuses, seemingly identical to lymphatic lacunae, ${ }^{38}$ were located in a chain next to and connected to paravertebral lymphatics (Figure 4A). Lymphatic valves were present in paravertebral lymphatics (Figure 4B) and in lymphatics that connected them to lymphatic plexuses (Figure 4B). The polarized structure of valves, the leaflets of which pointed downstream, revealed the direction of normal lymphatic flow, which was from caudal to rostral in paravertebral lymphatics and from lymphatic plexuses into paravertebral lymphatics via small connecting lymphatics. Some superficial lymphatic vessels that connected paravertebral lymphatics to the thoracic duct were found in young Prox1-GFP mice that had little adipose tissue (Figure 4C). However, many of these connecting vessels were probably missed because the GFP fluorescence from deeper lymphatics was obscured by overlying tissue (Figure 4C).

The location and spacing of lymphatic plexuses in ADN-VEGF-C mice resembled the segmental spacing of leakage sites (Figure 3, C and E). Superimposition of images of tracer fluorescence at the end of time-lapse videos and corresponding images of LYVE-1 staining of the same specimens revealed the coincidence of lymphatic plexuses and regions of diffuse tracer at leakage sites (Figure 4D). Measurements revealed that lymphatic plexuses in mice with chylothorax were significantly larger than the plexuses in Prox1-GFP control mice (Figure 4, E and F).

\section{Abnormalities of Paravertebral Lymphatics in ADN-VEGF-C Mice}

To learn more about lymphatic defects that led to retrograde flow, we compared the paravertebral lymphatic vessels of 


\section{A Thorax orientation}

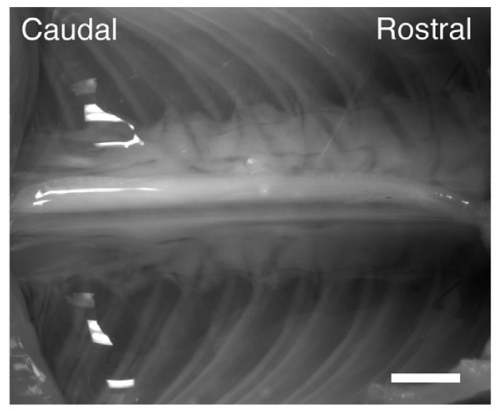

B

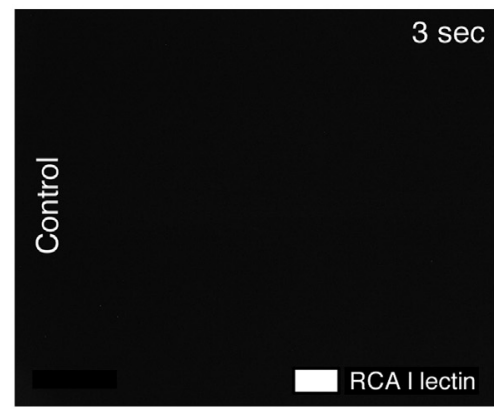

Control mouse, time-lapse frames

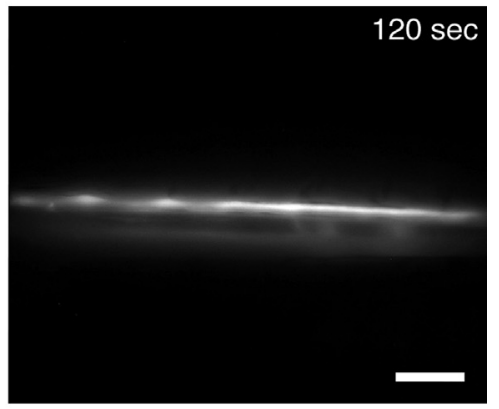

C

ADN-VEGF-C mouse, time-lapse frames

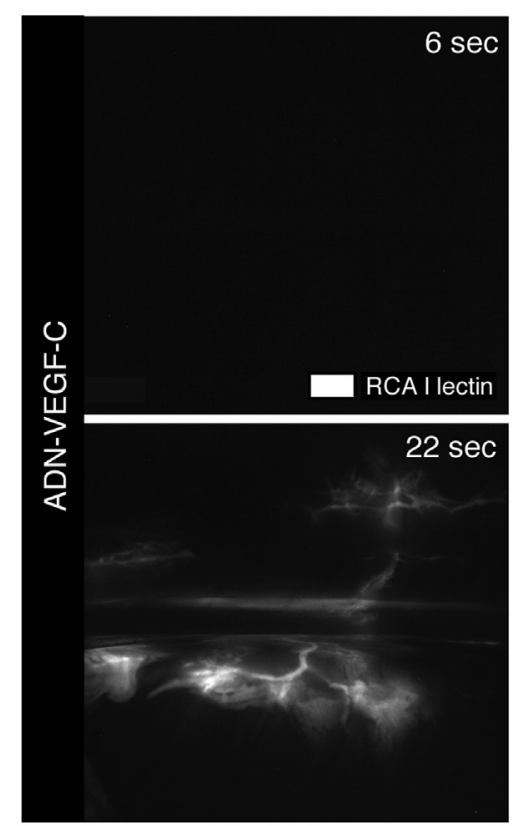

D

Comparison of tracer distribution
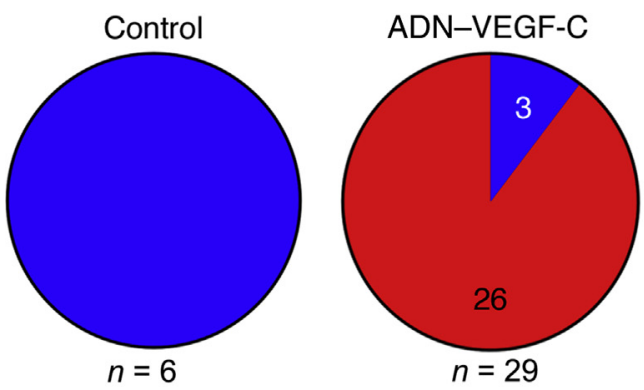

Fluorescence remained in thoracic duct

$\square$ Fluorescence immediately visible in paravertebral lymphatics
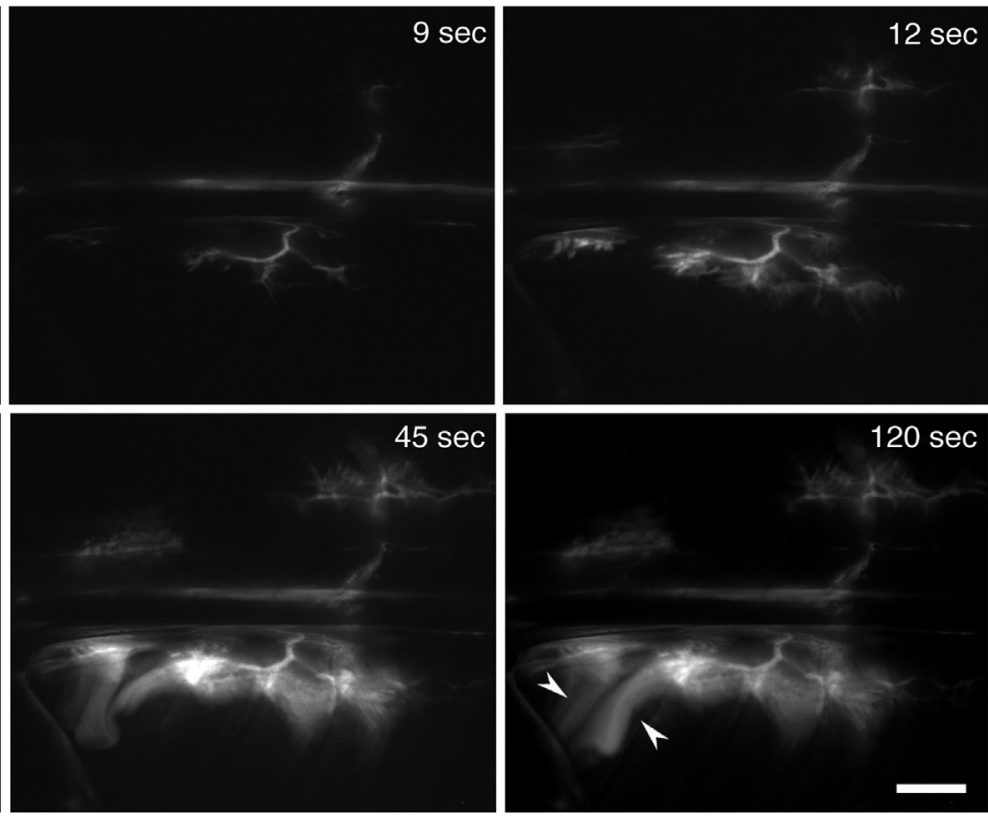

$\mathbf{E}$

\section{Video frames before and after thoracic cavity wash}
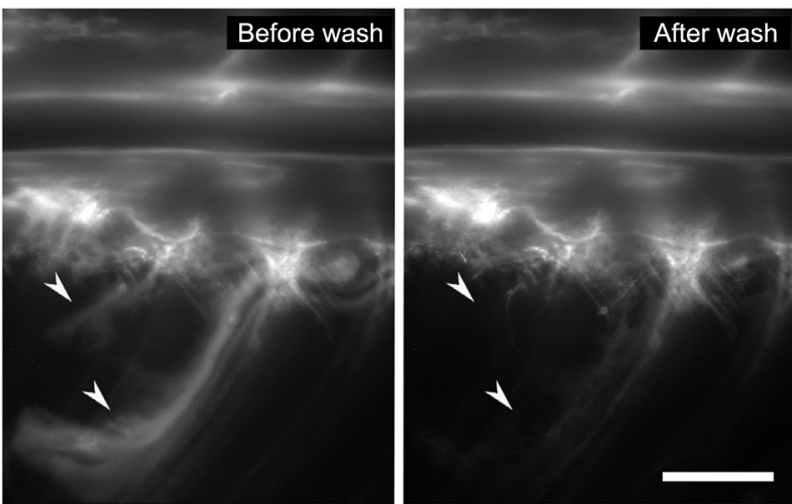

Figure 3 Retrograde fluorescent tracer flow into lymphatic plexuses and thoracic cavity. Image orientation: caudal (left), rostral (right). A: Bright-field image of region captured by time-lapse microscopic imaging. B: First frame at 3 seconds (left panel) after start of injection and last frame at 120 seconds (right panel) of a time-lapse video showing fluorescent Ricinus communis agglutinin I (RCA I) lectin (white) confined to thoracic duct of control mouse. C: Time-lapse video frames of ADN-VEGF-C mouse showing rapid movement of tracer out of thoracic duct (9 seconds), into adjacent lymphatics (22 seconds), and leakage into the thoracic cavity ( 45 and 120 seconds). Arrowheads mark diffuse extravasated tracer. D: Fluorescent lectin was confined to thoracic duct (blue), and not present in paravertebral lymphatics, in $100 \%$ of six single transgenic control mice, but was found in paravertebral lymphatics (red) within 6 seconds (two frames) after reaching the thoracic duct of $26(90 \%)$ of 29 ADN-VEGF-C mice. E: Images of fluorescent tracer leakage before (left panel, 120 seconds after injection) and after (right panel) PBS wash of pleural surface showing that some tracer was removed (arrowheads), consistent with entry into the thoracic cavity. $n=6$ mice (E). Scale bar $=2 \mathrm{~mm}(\mathbf{A}-\mathbf{C}$ and $\mathbf{E})$. 


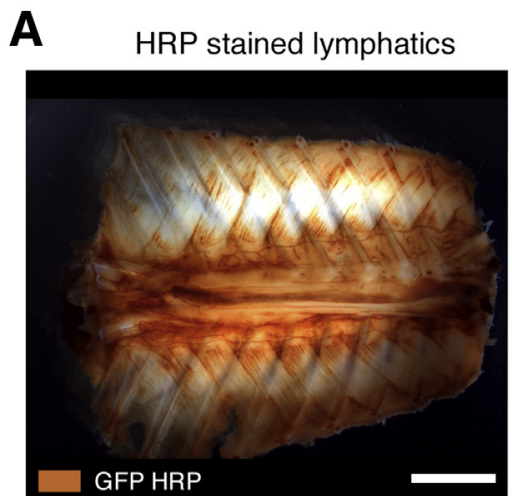

Drawing of HRP stained lymphatics

B Lymphatic plexus enlarged
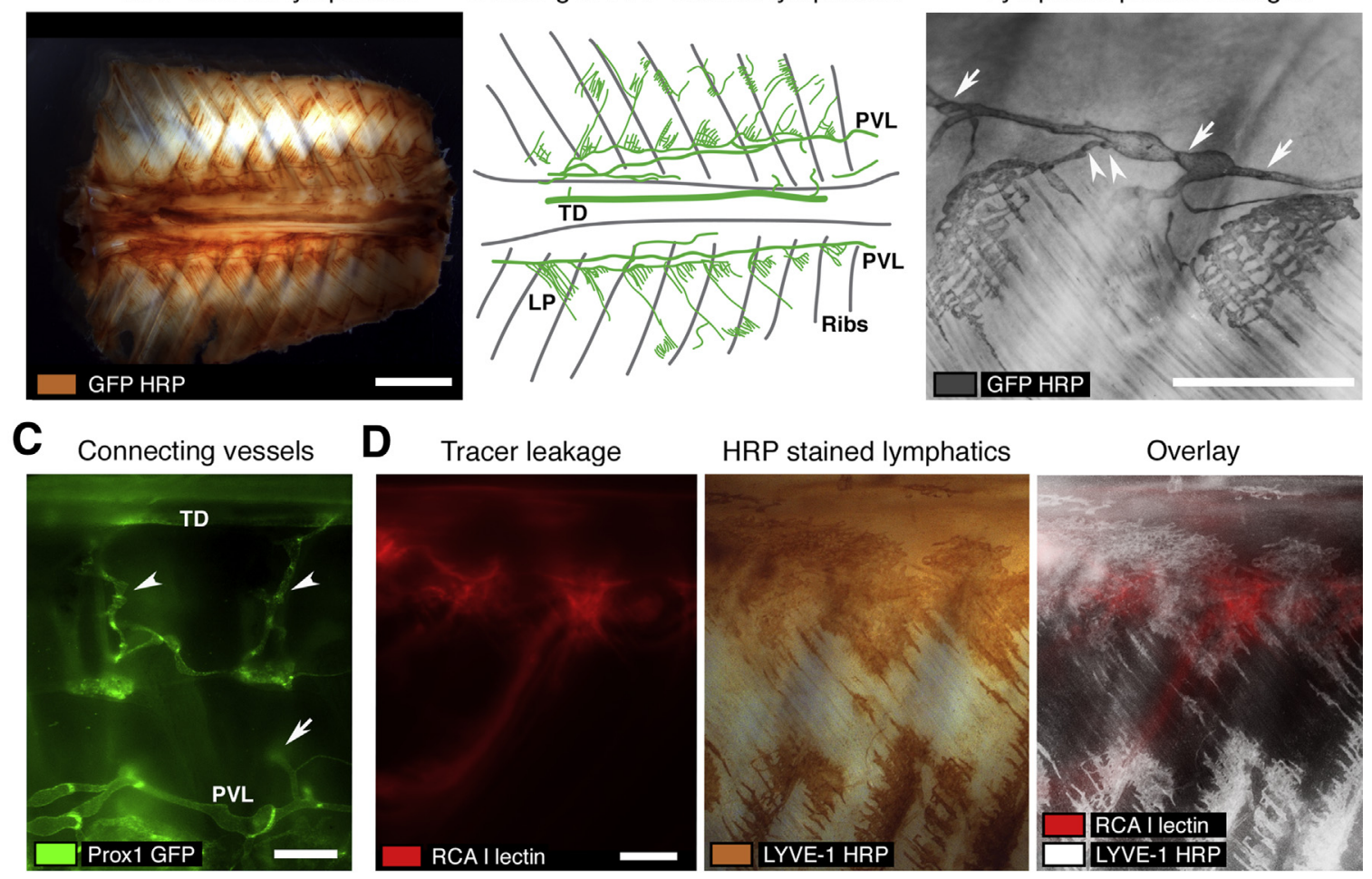

$\mathbf{E}$

Paravertebral lymphatic plexus architecture
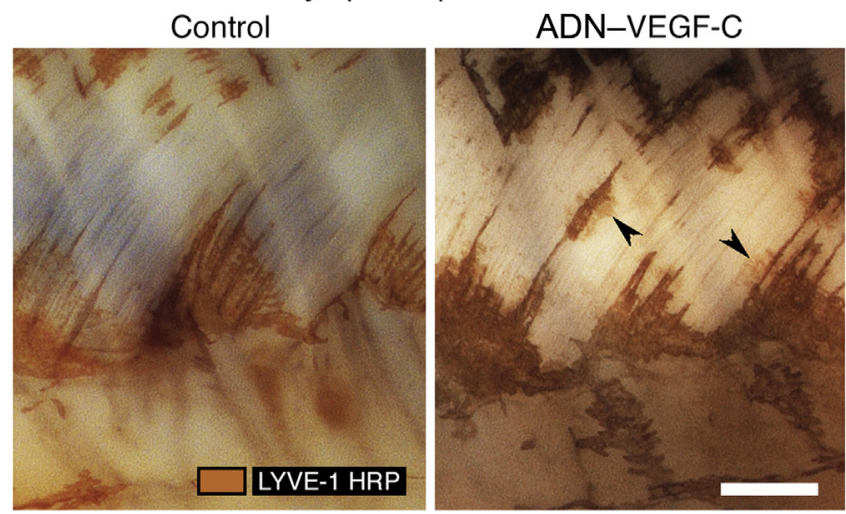

Paravertebral lymphatic plexus area
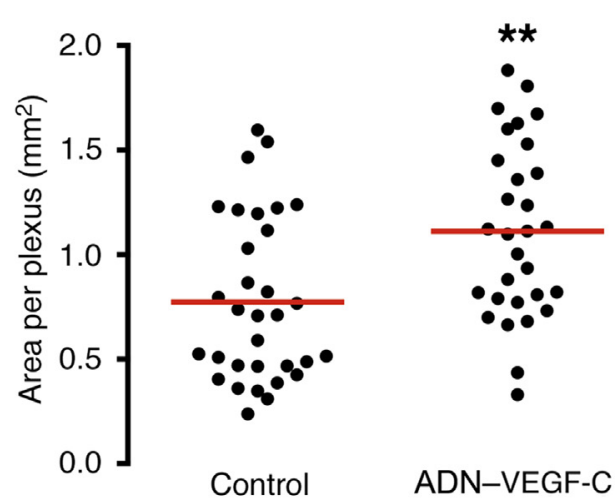

Figure 4 Coincidence of subpleural lymphatic plexuses and leakage sites. Image orientation: caudal (left), rostral (right). ADN-VEGF-C mice were analyzed after $0.075 \mathrm{mg} / \mathrm{mL}$ doxycycline for 7 days. A: Left panel: Whole mount of dorsal surface of thorax of Prox1-GFP control mouse after horseradish peroxidase (HRP) staining for GFP. Right panel: Drawing of whole mount where green lines show GFP ${ }^{+}$lymphatic vessels [thoracic duct (TD), paravertebral lymphatic vessel (PVL), and lymphatic plexus (LP)]. Gray lines mark the location of ribs. B: Paravertebral lymphatic vessel (arrows indicate valves) and connecting lymphatic (arrowheads indicate valves) to subpleural lymphatic plexuses. C: Fluorescence stereomicroscopic image of the pleural surface of the chest wall of a 3-week-old Prox1-GFP mouse showing lymphatic vessels (green; arrowheads) that connect the TD to PVLs. Some regions of the connecting lymphatics (arrow) are obscured by overlying tissue. D: Images of a region of chest wall showing sites of tracer leakage (red; left panel), LYVE-1-HRP staining of lymphatic plexuses (brown; middle panel), and an overlay of the two (white; LYVE-1-HRP; right panel). E: Enlarged images of lymphatic plexuses (LYVE-1-HRP) in chest wall of single transgenic control mouse and ADN-VEGF-C mouse, the latter showing bud-like outgrowths (arrowheads). F: Regional area per lymphatic plexus in single-transgenic and ADN-VEGF-C mice. Each dot shows the area of one plexus. Red lines indicate plexus area means. $n=7$ mice (D); $n=4$ mice per group (E and $\mathbf{F}) .{ }^{* *} P<0.01$ ( $t$-test). Scale bars: $4 \mathrm{~mm}(\mathbf{A}) ; 1 \mathrm{~mm}(\mathbf{B}-\mathbf{E})$. RCA I, Ricinus communis agglutinin I.

ADN-VEGF-C/Prox1-GFP mice and Prox1-GFP control mice in whole mounts stained for GFP (Figure 5A). Paravertebral lymphatics in ADN-VEGF-C/Prox1-GFP mice were on average $25 \%$ wider than corresponding lymphatics in control mice $(98 \pm 9$ versus $78 \pm 11 \mu \mathrm{m}$ ) (Figure $5 \mathrm{~B}$ ). Paravertebral lymphatics in ADN-VEGF-C mice also had bud-like outgrowths from the abluminal surface, which were not found in Prox1-GFP control mice (Figure 5, A and C). In addition, paravertebral lymphatics of ADN-VEGF-C/ Prox1-GFP mice had 54\% fewer lymphatic valves than control mice (1.3 versus 0.6 valves $/ \mathrm{mm}$ vessel length) (Figure 5, A and D). 

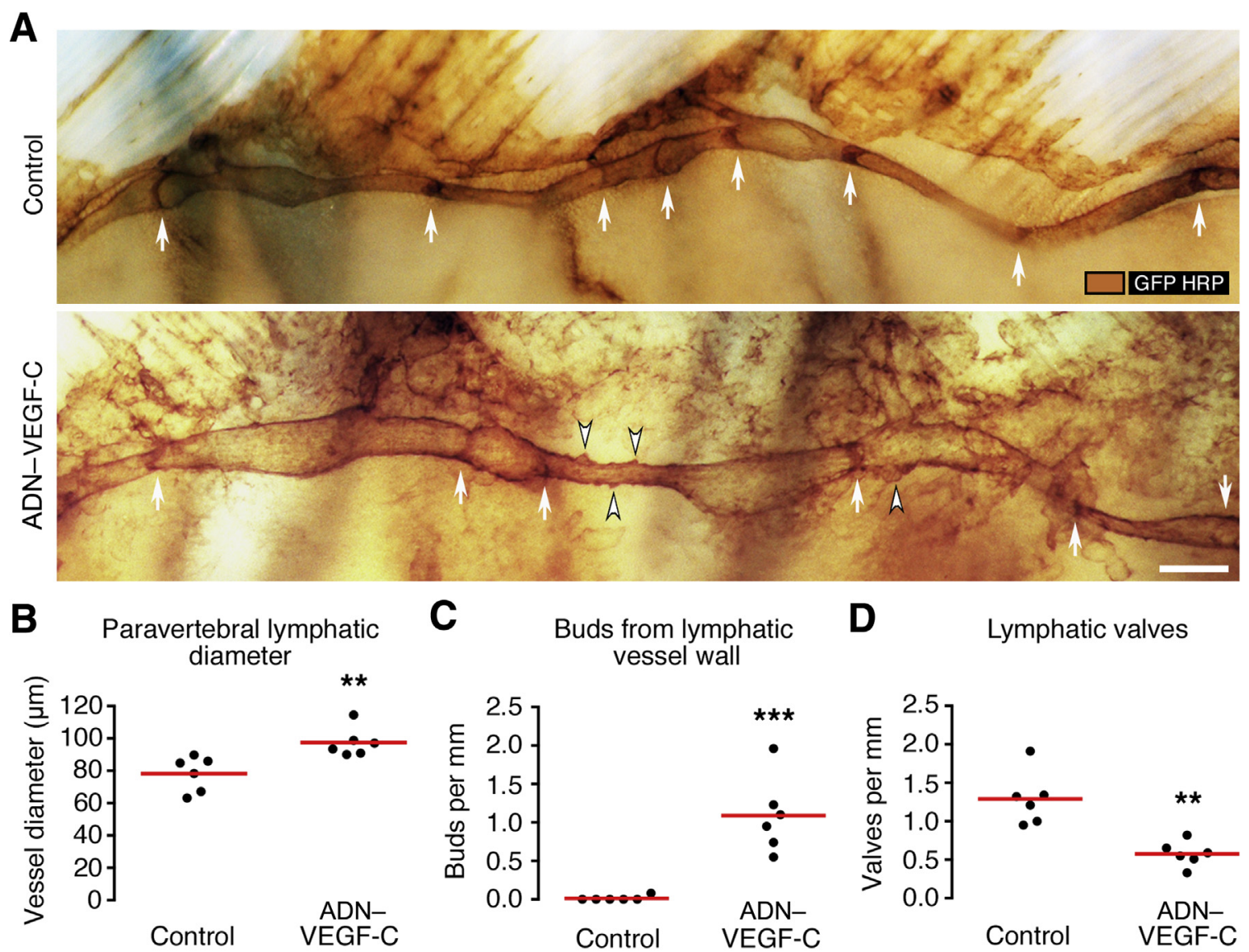

D

Lymphatic valves
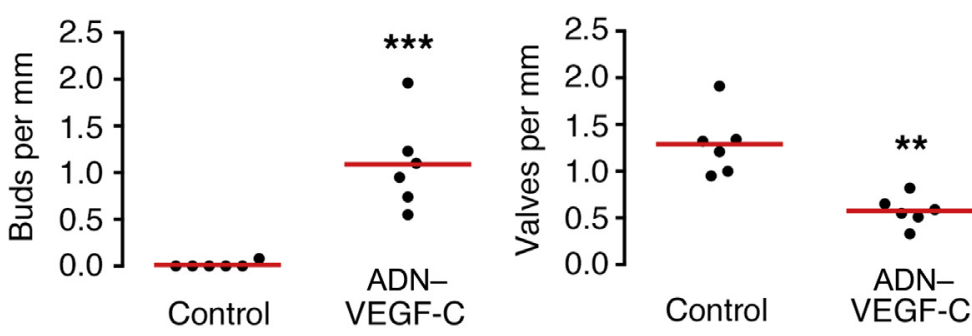

Figure 5 Abnormalities of paravertebral lymphatics in ADN-VEGF-C mice. Paravertebral lymphatics [brown; GFP-horseradish peroxidase (HRP)] in Prox1GFP control and ADN-VEGF-C/Prox1-GFP littermates after $0.075 \mathrm{mg} / \mathrm{mL}$ doxycycline for 7 days. A: Thoracic wall whole mounts showing valves (arrows) in both examples, but bud-like lymphatic outgrowths (arrowheads) only in ADN-VEGF-C/Prox1-GFP mouse. Image orientation: caudal (left), rostral (right). B-D: Paravertebral lymphatics vessel diameter (B), number of bud-like outgrowths (C), and valves per millimeter vessel length (D). Each dot is the value for one paravertebral lymphatic (two vessels per mouse; three mice per group). Red lines indicate group means. ${ }^{* * P}<0.01,{ }^{* *} P<0.001$ ( $t$-test). Scale bar $=250 \mu \mathrm{m}(\mathbf{A})$.

\section{Pleural Mesothelial Exfoliation in ADN-VEGF-C Mice with Chylothorax}

Fluid and cells in the thoracic cavity normally reach subpleural lymphatics through stomata in the parietal mesothelium and underlying matrix. ${ }^{39,40}$ To explore possible routes for retrograde lymph flow from lymphatic plexuses into the thoracic cavity, we asked whether mesothelial stomata were larger or more numerous in the pleural mesothelium of ADN-VEGF-C mice with chylothorax. The pleural surface is covered by a continuous layer of flat to cuboidal mesothelial cells that are clearly evident by SEM imaging. ${ }^{41}$ Paravertebral lymphatics of control mice were located in regions of cuboidal mesothelium, where stomata were most abundant (Figure 6A). No stomata were found in more lateral regions covered by flat mesothelial cells (Figure 6A). Surprisingly, the pleural surface of ADN-VEGF-C mice after doxycycline for 7 days had large regions devoid of mesothelial cells (sites of mesothelial exfoliation), where the underlying matrix was exposed (Figure 6B). The exposed matrix had many openings (foramina) approximately the size of stomata $^{42}$ (Figure $6 \mathrm{~B}$ ). A time course study revealed that mesothelial cell exfoliation was first evident on day 3 of doxycycline, which coincided with the first detection of chylothorax (Figure 1D and Figure 6C). The amount of exfoliation increased from $2.3 \%$ of the parietal pleural surface on day 3 , to $8.6 \%$ on day 5 , and to $12.8 \%$ on day 7 (Figure 6C). The distribution of mesothelial exfoliation over the pleural surface of the dorsal chest wall of three ADN-VEGF-C mice on doxycycline for 3 days was determined from SEM images (Materials and Methods). The distribution of lymphatic plexuses was similarly determined from stereomicroscopic images of Prox1-GFP control mice. This approach revealed that exfoliation was largely restricted to two regions of the dorsal surface of the chest wall, one aligned with paravertebral lymphatic plexuses and the other in a parallel but more lateral location (Figure 6, D and E). The location and coincidence of the regions with the distribution of lymphatic plexuses was more distinct on days 5 and 7 (Figure 6, D and E).

To determine whether the presence of chyle in the thoracic cavity can directly lead to exfoliation of pleural mesothelial cells, we injected $500 \mu \mathrm{L}$ of PBS or chyle, aspirated from the thorax of ADN-VEGF-C mice after 
A

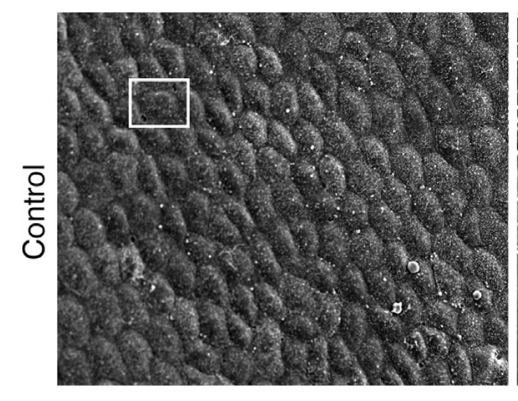

B

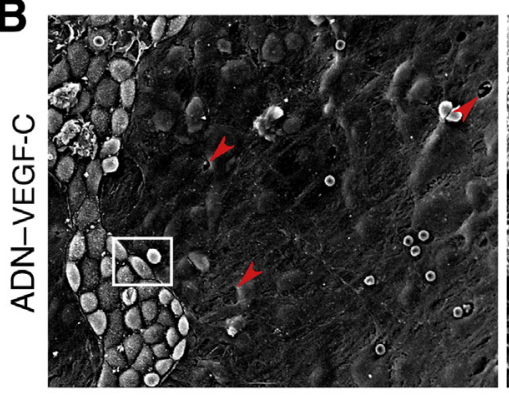

Surface of pleural mesothelium
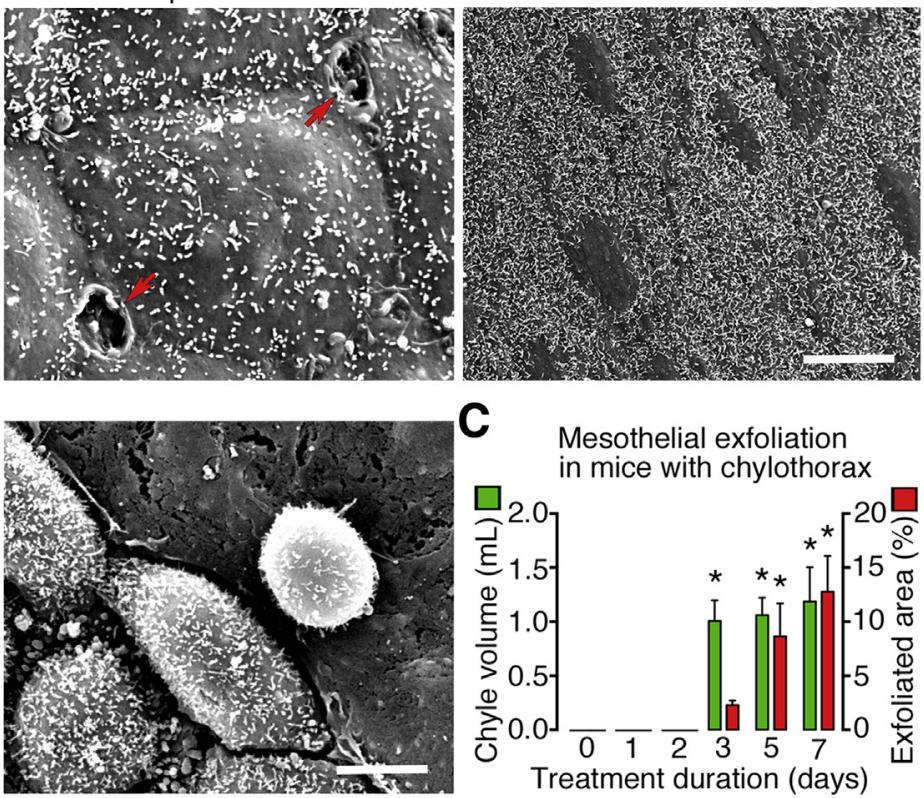

C

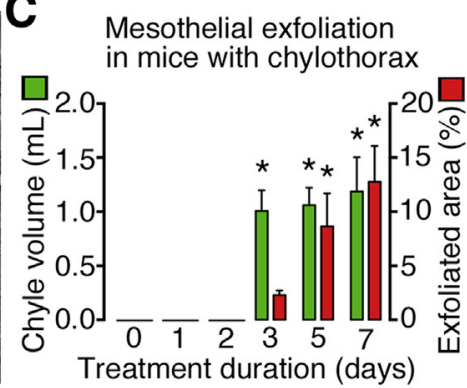

D

Regions of mesothelial cell exfoliation in ADN-VEGF-C mice

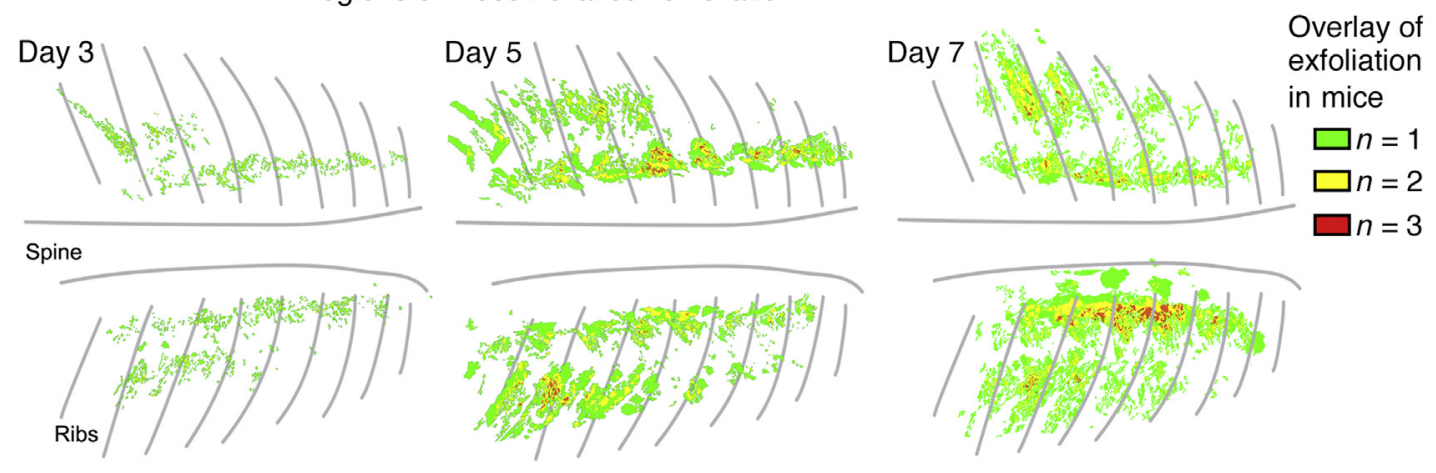

E

Location of lymphatic plexuses in Prox1-GFP control mice

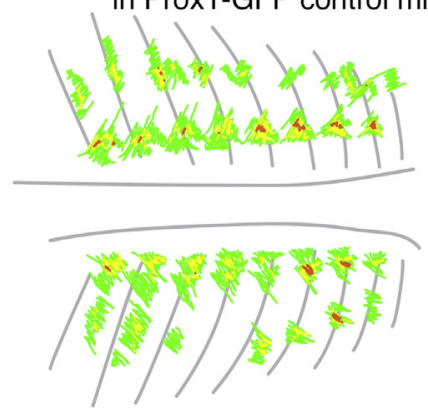

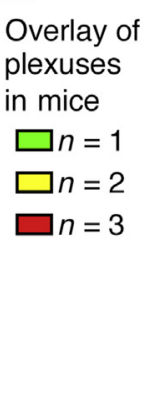

$\mathbf{F}$

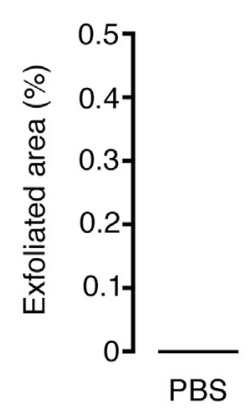

Intrathoracic injection of chyle

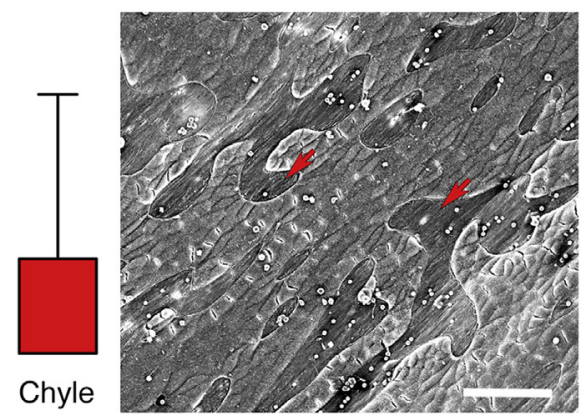

Figure 6 Pleural mesothelial stomata and exfoliation in ADN-VEGF-C mice. A and B: Scanning electron microscopic (SEM) images of pleural mesothelium of control mouse (A) and ADN-VEGF-C mouse on $0.075 \mathrm{mg} / \mathrm{mL}$ doxycycline for 7 days (B). A: Left panel: Cuboidal mesothelial surface of parietal pleura. Middle panel: Boxed area from left panel shown at higher magnification, indicating two lymphatic stomata (arrows). Right panel: Flat mesothelial surface of parietal pleura. No stomata are present in this region. B: ADN-VEGF-C mouse. Left panel: Surface of parietal pleura showing large region lacking mesothelial cells but revealing foramina in matrix (arrowheads). Right panel: Boxed area from left panel shown at higher magnification, indicating abnormal mesothelial cells surrounded by region of exfoliation. C: Amount of mesothelial exfoliation and corresponding volume of chyle in the thorax of ADN-VEGF-C mice on doxycycline for 0 to 7 days. D: Drawings of exfoliated regions in three ADN-VEGF-C mice. Green marks regions of exfoliation in only one of the three mice; yellow, regions of colocalization of exfoliation in two of the three mice; and red, colocalization in all three mice. E: Drawings of the location of lymphatic plexuses in three Prox1GFP control mice, as in D. F: Comparison of amount of mesothelial exfoliation 24 hours after intrathoracic injection of phosphate-buffered saline (PBS) or chyle in wild-type mice. SEM image of exfoliated region after intrathoracic injection of chyle into a wild-type mouse (arrows). $n=2$ mice per group (C, chyle volume on day 7 ); $n=3$ or 4 mice per group (B and $\mathbf{C}$, other groups); $n=3$ mice per group (F). ${ }^{*} P<0.05$ versus values for days $0,1,2$, and 3 and for chyle volumes on days 0,1 , and 2 (one-way analysis of variance). Scale bars: $60 \mu \mathrm{m}$ (A, left and right panels, B, left panel, and $\mathbf{F}$ ); $5 \mu \mathrm{m}$ (A, middle panel, and $\mathbf{B}$, right panel). 
5 days of doxycycline, into the pleural space of anesthetized Prox1-GFP control mice. The pleural surface was examined by SEM 24 hours later. Exfoliation of pleural mesothelium was detected in one of the three mice that received chyle but in none of the three mice injected with PBS (Figure 6F). No chyle or PBS was detected in the thoracic cavity of any mice at 24 hours after the injection, consistent with fluid removal by pleural lymphatics.

\section{Discussion}

Our goal was to use newly generated ADN-VEGF-C mice to determine how lymphatic abnormalities result in chylothorax. In these mice, VEGF-C was overexpressed in adipocytes after doxycycline exposure. As expected, the mice had lymphangiogenesis in adipose tissue, but unexpectedly they rapidly and consistently developed chylothorax that could be lethal. Real-time imaging revealed that a fluorescent tracer, which was normally confined to the thoracic duct, flowed retrograde from the thoracic duct into enlarged paravertebral lymphatics with fewer valves and from there into expanded lymphatic plexuses. The tracer extravasated from the lymphatic plexuses, traversed exfoliated regions of pleural mesothelium, and entered the thoracic cavity.

Chylothorax occurs in many mouse models that have lymphatic vessel malformations and defective lymphatic valves. ${ }^{18,20-28,43}$ These include mice with mutations in ephrinB2/ephrin type-B receptor 4 signaling or integrin $\alpha 9$ that correspond to human lymphatic defects accompanied by chylothorax or hydrops fetalis. ${ }^{14,15,19,20,24}$ Retrograde flow has been proposed as a mechanism of chylothorax in some mutant mice. ${ }^{21,24,25,43}$ However, limited information has been obtained to link the lymphatic abnormalities to chylothorax. Among the challenges, chylothorax is difficult to study because it is unpredictable or occurs during the neonatal period and is soon followed by death. Because VEGF-C expression in ADN-VEGF-C mice could be controlled by adjusting the doxycycline concentration and duration, we were able to develop a protocol in which chylothorax developed rapidly and consistently in otherwise normal adult mice. This approach excluded developmental abnormalities in the lymphatic vasculature and enabled the identification of defects in lymphatic vascular architecture and abnormal lymph flow patterns.

We used time-lapse fluorescence stereomicroscopy to follow the direction of flow of fluorescent Ricinus communis agglutinin I lectin tracer visible in the opened chest after controlled injection into a mesenteric lymph node immediately after euthanasia. This approach enabled us to follow the flow anterograde (normal) into the thoracic duct and retrograde (abnormal) into paravertebral lymphatics and the thoracic cavity under conditions that are not currently possible in living mice. Injections were made with standardized pressure and flow for meaningful comparison of ADN-VEGF-C mice to control mice. Lymphatic pumping was not observed and was assumed to make little or no contribution under these conditions. Time-lapse videos of flow patterns revealed that the tracer was confined to the thoracic duct in control mice but flowed from the thoracic duct into paravertebral lymphatics in ADN-VEGF-C mice.

Time-lapse video imaging revealed the presence of the tracer in paravertebral lymphatics a few seconds after it entered the thoracic duct of 26 of 29 ADN-VEGF-C mice on doxycycline for 7 days. Extravasation into the thoracic cavity was also almost immediate. The rapid entry of the tracer into paravertebral lymphatics and the thoracic cavity is consistent with retrograde flow from the thoracic duct. Although connections between the thoracic duct and paravertebral lymphatics were not always visible because of overlying adipose tissue, the almost simultaneous appearance of the tracer in the thoracic duct, paravertebral lymphatics, and thoracic cavity favored direct flow over leakage and reuptake or other routes. Paracrine effects of VEGF-C from adipocytes located near the thoracic duct and adjacent lymphatic vessels are likely to contribute to the development of chylothorax in adult ADN-VEGF-C mice. By comparison, chylothorax has an incidence of only $20 \%$ in a model of VEGF-C overexpression driven by the club cell secretory protein-promoter in airway and lung epithelial cells, even when doxycycline is started at postnatal day $0 .{ }^{44}$ Chylothorax does not occur in club cell secretory protein-VEGF-C mice when doxycycline, at $>10$ times the concentration used for most experiments in the present study, is started after postnatal day $7 .^{44}$

Chylothorax is found in many transgenic mice that have abnormalities in lymphatic valves ${ }^{18,20-22,43}$ or lymphatic vessels. ${ }^{23,26,27}$ Our studies of paravertebral lymphatics in ADN-VEGF-C/Prox1-GFP mice revealed fewer valves and other structural abnormalities. Paravertebral lymphatics and the lymphatic plexuses associated with them were enlarged and had bud-like outgrowths, consistent with the mitogenic action of VEGF-C on lymphatic endothelial cells. ${ }^{45,46}$ Lymphatic enlargement due to endothelial cell proliferation has also been reported in RAS p21 protein activator 1 -overexpressing mice that develop chylothorax. ${ }^{27}$

Lymphatic enlargement promoted by VEGF-C overexpression could affect valve competence ${ }^{25}$ and contribute to chylothorax. However, it does not explain the reduction in lymphatic valve frequency in ADN-VEGF-C mice. Lymphatic endothelial cells covering valves have been reported to have higher VEGF receptor-3 expression. ${ }^{47}$ Exaggerated proliferation of these endothelial cells could make valves defective and nonfunctional. As lymph flow is essential for normal valve development and maintenance, ${ }^{28,48}$ disturbed lymph flow in paravertebral lymphatics due to malformed upstream lymphatics could also contribute to valve defects.

Chylous ascites was found in $60 \%$ of ADN-VEGF-C mice after doxycycline for 3 days, but was uncommon $(<3 \%)$ at 7 days when chylothorax was always present. Among the mechanisms that could explain the transient nature of chylous ascites in these mice are maturation of 
new mesenteric lymphatics to a less leaky phenotype and changes in hydrostatic forces that favor drainage away from the abdomen into the thoracic duct. In support of the former, brief treatment with adenoviral VEGF-C induces lymphatic vessel leakiness, but the lymphatics become more mature and less leaky over time. ${ }^{49}$ Valve incompetence developing in thoracic lymphatics after 3 days of VEGF-C overexpression could favor retrograde drainage of chyle from the thoracic duct into subpleural lymphatics. Factors that contribute to regional differences in lymphatic growth and abnormalities by governing protease processing of VEGF-C to its active form ${ }^{50,51}$ also deserve further study in this context.

As subpleural lymphatics are sites of fluid uptake, ${ }^{38,52,53}$ and endothelial cells of initial lymphatics have more permeable junctions, ${ }^{54,55}$ these lymphatics are the likely preferred sites of extravasation into the chest cavity in the setting of retrograde chyle flow.

Removal of pleural fluid by lymphatic drainage through mesothelial stomata is an important but not the only route of fluid clearance from the thoracic cavity. ${ }^{39,40}$ Fluid can be absorbed by blood vessels of the visceral pleura or taken up by mesothelial cells. Fluid transport through the lymphatic system can increase greatly in conditions of increased pleural fluid load; however, clearance via other routes is considered more constant. ${ }^{40,56}$ Cells and macromolecules are thought to leave the thoracic cavity exclusively through mesothelial stomata and subpleural lymphatics. ${ }^{57-59}$

Chyle could induce exfoliation of the pleural mesothelium in mice with chylothorax by direct toxic effects or otherwise altering the attachment of mesothelial cells. Intrathoracic injection of chyle resulted in mesothelial cell exfoliation, albeit in only one of three mice tested. However, the exposure was brief because no chyle was detected in the chest 1 day after injection, probably because of efficient lymphatic uptake of pleural fluid in these normal mice. In contrast, the loss of mesothelium in ADN-VEGF-C mice with chylothorax reflected sustained exposure over several days.

Thoracic duct lymph contains fatty acids, of which oleic acid and linoleic acid are most abundant. ${ }^{2}$ Cytotoxic effects of fatty acids in chyle could contribute to mesothelial exfoliation. Cytotoxic effects of free fatty acids in lymph can suppress lymphocyte responses ${ }^{60}$ and kill endothelial cells in vitro. ${ }^{61}$

Exfoliation was greatest near lymphatic plexuses. The subpleural matrix exposed by exfoliation of the mesothelium had many round openings, which are called foramina. ${ }^{42}$ It is tempting to conclude that these openings align with mesothelial stomata, mark the drainage route for fluid from the thoracic cavity into subpleural lymphatic plexuses, and are preferential sites of mesothelial detachment when lymph flows retrograde into the thoracic cavity.

The functional consequences of retrograde lymphatic flow due to underlying lymphatic vessel abnormalities have been considered for many years in patients with chylothorax..$^{29,30}$ Retrograde chyle flow from the thoracic duct toward peribronchial lymphatics and lung parenchyma is documented by dynamic contrast-enhanced magnetic resonance lymphangiography in 16 of 18 patients with plastic bronchitis after surgical correction of congenital heart disease. ${ }^{32}$ Most of these patients had chylothorax. The findings are evidence of retrograde lymph flow in pulmonary lymphatics of patients with chylothorax.

ADN-VEGF-C mice had normal lymphatics until VEGF-C expression was triggered by doxycycline. All changes that led to chylothorax occurred within 7 days. At that time, the mice had conspicuous lymphatic vessel abnormalities. Chylothorax appeared to result primarily from lymphatic enlargement, valve defects, and retrograde flow from the thoracic duct into subpleural lymphatics in the chest wall. Lymphatic valve insufficiency could be a common underlying cause of chylothorax in transgenic mice with lymphatic malformations, even when the genetic abnormality does not directly affect valve development.

From these studies, we conclude that chylothorax in ADN-VEGF-C mice results from retrograde flow of chyle from the thoracic duct into lymphatic plexuses, where it extravasates and enters the thoracic cavity. Retrograde flow is enabled by lymphatic enlargement, deformation, or loss of lymphatic valves, and other lymphatic abnormalities promoted by VEGF-C overexpression. Chyle extravasation from inherently leaky lymphatic plexuses leads to exfoliation of the overlying pleural mesothelium, which could facilitate chyle entry into the thoracic cavity.

\section{Acknowledgments}

We thank Drs. Jason Rock and Matthew Donne (University of California San Francisco) for providing access to and help with the fluorescence stereomicroscope and video camera, Dr. Minah Kim for careful reading of the manuscript and valuable suggestions, and Mari Jokinen for technical help with experiments.

M.N., A.B., and S.K. designed and performed experiments, analyzed and interpreted results, and wrote the manuscript; M.A. analyzed data; K.A. provided tetO-VEGF-C mice; J.M.R. and P.E.S. provided ADN-rtTA mice and contributed to the manuscript; D.M.M. contributed to the overall design of experiments, data analysis, interpretation of results, and manuscript preparation.

\section{Supplemental Data}

Supplemental material for this article can be found at http://dx.doi.org/10.1016/j.ajpath.2017.05.009.

\section{References}

1. Zilversmit D: The composition and structure of lymph chylomicrons in dog, rat, and man. J Clin Invest 1965, 44:1610 
2. Escobedo N, Proulx ST, Karaman S, Dillard ME, Johnson N, Detmar M, Oliver G: Restoration of lymphatic function rescues obesity in Prox1-haploinsufficient mice. JCI Insight 2016, 1. pii: e85096

3. Soto-Martinez M, Massie J: Chylothorax: diagnosis and management in children. Paediatr Respir Rev 2009, 10:199-207

4. McGrath EE, Blades Z, Anderson PB: Chylothorax: aetiology, diagnosis and therapeutic options. Respir Med 2010, 104:1-8

5. Nilgun Koksal SD, Okan M, Gebitekin C, Senkaya I: Congenital chylothorax. Turk J Med Sci 2000, 30:307-309

6. Eddleman KA, Levine AB, Chitkara U, Berkowitz RL: Reliability of pleural fluid lymphocyte counts in the antenatal diagnosis of congenital chylothorax. Obstet Gynecol 1991, 78:530-532

7. Bawle EV, Black V: Nonimmune hydrops fetalis in Noonan's syndrome. Am J Dis Child 1986, 140:758-760

8. Hennekam RC, Geerdink RA, Hamel BC, Hennekam FA, Kraus P, Rammeloo JA, Tillemans AA: Autosomal recessive intestinal lymphangiectasia and lymphedema, with facial anomalies and mental retardation. Am J Med Genet 1989, 34:593-600

9. Rocha G: Pleural effusions in the neonate. Curr Opin Pulm Med 2007, 13:305-311

10. Schlüter G, Steckel M, Schiffmann H, Harms K, Viereck V, Emons G, Burfeind P, Pauer HU: Prenatal DNA diagnosis of Noonan Syndrome in a fetus with massive hygroma colli, pleural effusion and ascites. Prenat Diagn 2005, 25:574-576

11. Tie M, Poland GA, Rosenow EC: Chylothorax in Gorham's syndrome: a common complication of a rare disease. Chest 1994, 105: 208-213

12. Alders M, Hogan BM, Gjini E, Salehi F, Al-Gazali L, Hennekam EA, Holmberg EE, Mannens MM, Mulder MF, Offerhaus GJ, Prescott TE, Schroor EJ, Verheij JB, Witte M, Zwijnenburg PJ, Vikkula M, Schulte-Merker S, Hennekam RC: Mutations in CCBE1 cause generalized lymph vessel dysplasia in humans. Nat Genet 2009, 41:1272-1274

13. Irrthum A, Devriendt K, Chitayat D, Matthijs G, Glade C, Steijlen PM, Fryns JP, Van Steensel MA, Vikkula M: Mutations in the transcription factor gene SOX18 underlie recessive and dominant forms of hypotrichosis-lymphedema-telangiectasia. Am J Hum Genet 2003, 72:1470-1478

14. Ma GC, Liu CS, Chang SP, Yeh KT, Ke YY, Chen TH, Wang BB, Kuo SJ, Shih JC, Chen M: A recurrent ITGA9 missense mutation in human fetuses with severe chylothorax: possible correlation with poor response to fetal therapy. Prenat Diagn 2008, 28:1057-1063

15. Martin-Almedina S, Martinez-Corral I, Holdhus R, Vicente A, Fotiou E, Lin S, Petersen K, Simpson MA, Hoischen A, Gilissen C, Jeffery H, Atton G, Karapouliou C, Brice G, Gordon K, Wiseman JW, Wedin M, Rockson SG, Jeffery S, Mortimer PS, Snyder MP, Berland S, Mansour S, Makinen T, Ostergaard P: EPHB4 kinase-inactivating mutations cause autosomal dominant lymphaticrelated hydrops fetalis. J Clin Invest 2016, 126:3080-3088

16. Bos FL, Caunt M, Peterson-Maduro J, Planas-Paz L, Kowalski J, Karpanen T, van Impel A, Tong R, Ernst JA, Korving J, van Es JH, Lammert E, Duckers HJ, Schulte-Merker S: CCBE1 is essential for mammalian lymphatic vascular development and enhances the lymphangiogenic effect of vascular endothelial growth factor-C in vivo. Circ Res 2011, 109:486-491

17. Francois M, Caprini A, Hosking B, Orsenigo F, Wilhelm D, Browne C, Paavonen K, Karnezis T, Shayan R, Downes M, Davidson T, Tutt D, Cheah KS, Stacker SA, Muscat GE, Achen MG, Dejana E, Koopman P: Sox18 induces development of the lymphatic vasculature in mice. Nature 2008, 456:643-647

18. Bazigou E, Xie S, Chen C, Weston A, Miura N, Sorokin L, Adams R, Muro AF, Sheppard D, Makinen T: Integrin-alpha 9 is required for fibronectin matrix assembly during lymphatic valve morphogenesis. Dev Cell 2009, 17:175-186

19. Zhang G, Brady J, Liang WC, Wu Y, Henkemeyer M, Yan M: Ephb4 forward signalling regulates lymphatic valve development. Nat Commun 2015, 6:6625
20. Huang XZ, Wu JF, Ferrando R, Lee JH, Wang YL, Farese RV Jr, Sheppard D: Fatal bilateral chylothorax in mice lacking the integrin alpha9beta1. Mol Cell Biol 2000, 20:5208-5215

21. Kanady JD, Dellinger MT, Munger SJ, Witte MH, Simon AM: Connexin37 and Connexin 43 deficiencies in mice disrupt lymphatic valve development and result in lymphatic disorders including lymphedema and chylothorax. Dev Biol 2011, 354:253-266

22. Sabine A, Bovay E, Demir CS, Kimura W, Jaquet M, Agalarov Y, Zangger N, Scallan JP, Graber W, Gulpinar E, Kwak BR, Makinen T, Martinez-Corral I, Ortega S, Delorenzi M, Kiefer F, Davis MJ, Djonov V, Miura N, Petrova TV: FOXC2 and fluid shear stress stabilize postnatal lymphatic vasculature. J Clin Invest 2015, 125: 3861-3877

23. Ayadi A, Zheng H, Sobieszczuk P, Buchwalter G, Moerman P, Alitalo K, Wasylyk B: Net-targeted mutant mice develop a vascular phenotype and up-regulate egr-1. EMBO J 2001, 20:5139-5152

24. Makinen T, Adams RH, Bailey J, Lu Q, Ziemiecki A, Alitalo K, Klein R, Wilkinson GA: PDZ interaction site in ephrinb2 is required for the remodeling of lymphatic vasculature. Genes Dev 2005, 19 : 397-410

25. Harvey NL, Srinivasan RS, Dillard ME, Johnson NC, Witte MH, Boyd K, Sleeman MW, Oliver G: Lymphatic vascular defects promoted by Prox 1 haploinsufficiency cause adult-onset obesity. Nat Genet 2005, 37:1072-1081

26. Ichise T, Yoshida N, Ichise H: H-, N- and Kras cooperatively regulate lymphatic vessel growth by modulating VEGFR3 expression in lymphatic endothelial cells in mice. Development 2010, 137: $1003-1013$

27. Lapinski PE, Kwon S, Lubeck BA, Wilkinson JE, Srinivasan RS, Sevick-Muraca E, King PD: RASA1 maintains the lymphatic vasculature in a quiescent functional state in mice. J Clin Invest 2012, 122:733-747

28. Sweet DT, Jimenez JM, Chang J, Hess PR, Mericko-Ishizuka P, Fu J, Xia L, Davies PF, Kahn ML: Lymph flow regulates collecting lymphatic vessel maturation in vivo. J Clin Invest 2015, 125:2995-3007

29. Kinmonth JB, Taylor GW: Chylous reflux. Br Med J 1964, 1: 529-532

30. Maier HC: Chylous reflux in the lungs and pleurae. Thorax 1968, 23 : 281-296

31. Orliaguet $\mathrm{O}$, Beauclair $\mathrm{P}$, Gavazzi G, Winckel P, Laporte F, Coulomb M, Ferretti GR: Thoracic lymphangiectasis presenting with chyloptysis and bronchial cast expectoration. Eur Radiol 2002, 12 Suppl 3:S162-S165

32. Dori Y, Keller MS, Rome JJ, Gillespie MJ, Glatz AC, Dodds K, Goldberg DJ, Goldfarb S, Rychik J, Itkin M: Percutaneous lymphatic embolization of abnormal pulmonary lymphatic flow as treatment of plastic bronchitis in patients with congenital heart disease. Circulation 2016, 133:1160-1170

33. Wang ZV, Deng Y, Wang QA, Sun K, Scherer PE: Identification and characterization of a promoter cassette conferring adipocyte-specific gene expression. Endocrinology 2010, 151:2933-2939

34. Lohela M, Helotera H, Haiko P, Dumont DJ, Alitalo K: Transgenic induction of vascular endothelial growth factor-C is strongly angiogenic in mouse embryos but leads to persistent lymphatic hyperplasia in adult tissues. Am J Pathol 2008, 173:1891-1901

35. Choi I, Chung HK, Ramu S, Lee HN, Kim KE, Lee S, Yoo J, Choi D, Lee YS, Aguilar B, Hong YK: Visualization of lymphatic vessels by Prox1-promoter directed GFP reporter in a bacterial artificial chromosome-based transgenic mouse. Blood 2011, 117: 362-365

36. Pfaffl MW: A new mathematical model for relative quantification in real-time RT-PCR. Nucleic Acids Res 2001, 29:e45

37. Lammoglia GM, Van Zandt CE, Galvan DX, Orozco JL, Dellinger MT, Rutkowski JM: Hyperplasia, de novo lymphangiogenesis, and lymphatic regression in mice with tissue-specific, inducible overexpression of murine VEGF-D. Am J Physiol Heart Circ Physiol 2016, 311:H384-H394 
38. Albertine KH, Wiener-Kronish JP, Staub NC: The structure of the parietal pleura and its relationship to pleural liquid dynamics in sheep. Anat Rec 1984, 208:401-409

39. Negrini D, Moriondo A: Pleural function and lymphatics. Acta Physiol (Oxf) 2013, 207:244-259

40. Agostoni E, Zocchi L: Pleural liquid and its exchanges. Respir Physiol Neurobiol 2007, 159:311-323

41. Wang ZB, Li M, Li JC: Recent advances in the research of lymphatic stomata. Anat Rec (Hoboken) 2010, 293:754-761

42. Li YY, Li JC: Ultrastructure and three-dimensional study of the lymphatic stomata in the costal pleura of the rabbit. Microsc Res Tech 2003, 62:240-246

43. Munger SJ, Davis MJ, Simon AM: Defective lymphatic valve development and chylothorax in mice with a lymphatic-specific deletion of Connexin43. Dev Biol 2017, 421:204-218

44. Yao LC, Testini C, Tvorogov D, Anisimov A, Vargas SO, Baluk P, Pytowski B, Claesson-Welsh L, Alitalo K, McDonald DM: Pulmonary lymphangiectasia resulting from VEGF-C overexpression during a critical period. Circ Res 2014, 114:806-822

45. Jeltsch M, Kaipainen A, Joukov V, Meng X, Lakso M, Rauvala H, Swartz M, Fukumura D, Jain RK, Alitalo K: Hyperplasia of lymphatic vessels in VEGF-C transgenic mice. Science 1997, 276: 1423-1425

46. Oh SJ, Jeltsch MM, Birkenhager R, McCarthy JE, Weich HA, Christ B, Alitalo K, Wilting J: VEGF and VEGF-C: specific induction of angiogenesis and lymphangiogenesis in the differentiated avian chorioallantoic membrane. Dev Biol 1997, 188:96-109

47. Liu X, Pasula S, Song H, Tessneer KL, Dong Y, Hahn S, Yago T, Brophy ML, Chang B, Cai X, Wu H, McManus J, Ichise H, Georgescu C, Wren JD, Griffin C, Xia L, Srinivasan RS, Chen H: Temporal and spatial regulation of epsin abundance and VEGFR3 signaling are required for lymphatic valve formation and function. Sci Signal 2014, 7:ra97

48. Kazenwadel J, Betterman KL, Chong CE, Stokes PH, Lee YK, Seeker GA, Agalarov Y, Demir CS, Lawrence DM, Sutton DL, Tabruyn SP, Miura N, Salminen M, Petrova TV, Matthews JM, Hahn CN, Seott HS, Harvey NL: GATA2 is required for lymphatic vessel valve development and maintenance. J Clin Invest 2015, 125: 2979-2994

49. Tammela T, Saaristo A, Holopainen T, Lyytikka J, Kotronen A, Pitkonen M, Abo-Ramadan U, Yla-Herttuala S, Petrova TV, Alitalo K: Therapeutic differentiation and maturation of lymphatic vessels after lymph node dissection and transplantation. Nat Med 2007, 13:1458-1466
50. Jeltsch M, Jha SK, Tvorogov D, Anisimov A, Leppanen VM, Holopainen T, Kivela R, Ortega S, Karpanen T, Alitalo K: CCBE1 enhances lymphangiogenesis via a disintegrin and metalloprotease with thrombospondin motifs-3-mediated vascular endothelial growth factor-C activation. Circulation 2014, 129: 1962-1971

51. Le Guen L, Karpanen T, Schulte D, Harris NC, Koltowska K, Roukens G, Bower NI, van Impel A, Stacker SA, Achen MG, Schulte-Merker S, Hogan BM: CCBE1 regulates VEGFC-mediated induction of VEGFR3 signaling during embryonic lymphangiogenesis. Development 2014, 141:1239-1249

52. Negrini D, Del Fabbro M, Gonano C, Mukenge S, Miserocchi G: Distribution of diaphragmatic lymphatic lacunae. J Appl Physiol (1985) 1992, 72:1166-1172

53. Grimaldi A, Moriondo A, Sciacca L, Guidali ML, Tettamanti G, Negrini D: Functional arrangement of rat diaphragmatic initial lymphatic network. Am J Physiol Heart Circ Physiol 2006, 291: H876-H885

54. Baluk P, Fuxe J, Hashizume H, Romano T, Lashnits E, Butz S, Vestweber D, Corada M, Molendini C, Dejana E, McDonald DM: Functionally specialized junctions between endothelial cells of lymphatic vessels. J Exp Med 2007, 204:2349-2362

55. Scallan JP, Davis MJ, Huxley VH: Permeability and contractile responses of collecting lymphatic vessels elicited by atrial and brain natriuretic peptides. J Physiol 2013, 591:5071-5081

56. Bodega F, Agostoni E: Contribution of lymphatic drainage through stomata to albumin removal from pleural space. Respir Physiol Neurobiol 2004, 142:251-263

57. Broaddus VC, Wiener-Kronish J, Berthiaume Y, Staub N: Removal of pleural liquid and protein by lymphatics in awake sheep. J Appl Physiol (1985) 1988, 64:384-390

58. Miserocchi G, Negrini D, Gonano C: Direct measurement of interstitial pulmonary pressure in in situ lung with intact pleural space. J Appl Physiol (1985) 1990, 69:2168-2174

59. Bodega F, Zocchi L, Agostoni E: Albumin transcytosis in mesothelium. Am J Physiol Lung Cell Mol Physiol 2002, 282:L3-L11

60. Kinoshita Y, Nagasawa T, Kimura S, Kageyama K, Kimura E: Cytotoxic effect of the thoracic-duct-lymph incubated on lymphocytes. Z Lymphol 1979, 3:74-78

61. Qin X, Dong W, Sharpe SM, Sheth SU, Palange DC, Rider T, Jandacek R, Tso P, Deitch EA: Role of lipase-generated free fatty acids in converting mesenteric lymph from a noncytotoxic to a cytotoxic fluid. Am J Physiol Gastrointest Liver Physiol 2012, 303: G969-G978 